(C) American Chemical Society, J. Am. Chem. Soc., JA043941A, Supporting Info Page S1

\title{
Periodic Mesoporous Organosilica with Large Heterocyclic Bridging Groups
}

\author{
Oksana Olkhovyk and Mietek Jaroniec* \\ Chemistry Department, Kent State University, Kent, Ohio 44242
}

\section{Experimental}

Poly(ethylene oxide)-poly(propylene oxide)-poly(ethylene oxide) triblock copolymer template $\left(\mathrm{EO}_{20} \mathrm{PO}_{70} \mathrm{EO}_{20}\right.$, Pluronic P123 from BASF), tetraethoxysilane (TEOS from Fluka), and tris[3-(trimethoxysilyl)propyl]isocyanurate (Aldrich) were used without additional purification. In typical synthesis, $4 \mathrm{~g}$ of Pluronic P123 was dissolved in $28 \mathrm{~mL}$ of deionized water and 120 $\mathrm{mL}$ of $2 \mathrm{M} \mathrm{HCl}$ under constant stirring for three hours prior to addition of the specified amounts of tris[3-(trimethoxysilyl)propyl]isocyanurate (ICS) and TEOS to achieve the desired molar ratio of these organosilanes. This mixture was further stirred for 24 hours before hydrothermal treatment at $100{ }^{\circ} \mathrm{C}$ for 48 hours. The resulting white precipitate was filtered followed by extraction of the polymeric template with ethanol/ $\mathrm{HCl}$ solution for 24 hours at $60^{\circ} \mathrm{C}$. Extraction solution contained $100 \mathrm{~mL}$ of $95 \%$ ethanol and $4 \mathrm{ml}$ of $12 \mathrm{M} \mathrm{HCl}$. Extraction was repeated for every sample twice.

The molar composition of the synthesis mixture was as follows: (1-x)M TEOS: xM ICS: $0.017 \mathrm{M}$ P123 Polymer: $188 \mathrm{M} \mathrm{H}_{2} \mathrm{O}: 5.8 \mathrm{M} \mathrm{HCl}$, where $\mathrm{x}$ denotes the number of moles of ICS. The synthesis of PMO materials was performed by using different percentage of ICS expressed per silicon atom to one mole of silica precursors, i.e., $p=100(3 x) \%=10,25,50,75$ and 90 . The resulting samples were denoted as PMO-ICS-p, where $\mathrm{p}$ is the percentage of tris[3(trimethoxysilyl)-propyl]isocyanurate) (ICS) as defined above.

\footnotetext{
*To whom correspondence should be addressed. Phone: (330) 672-3790. Fax: (330) 672-3816. E-mail: jaroniec@kent.edu
} 
(c) American Chemical Society, J. Am. Chem. Soc., JA043941A, Supporting Info Page S2

Table 1S. Parameters of periodic mesoporous organosilica (PMO) with bridged tris[3(trimethoxysilyl)propyl]isocyanurate (ISC).

\begin{tabular}{|c|c|c|c|c|c|}
\hline Sample & $\mathrm{S}_{\mathrm{BET}}\left(\mathrm{m}^{2} / \mathrm{g}\right)$ & $\mathrm{V}_{\mathrm{t}}\left(\mathrm{cm}^{3} / \mathrm{g}\right)$ & $\mathrm{d}(\mathrm{nm})$ & $\begin{array}{c}\text { Unit } \\
\text { cell parameter } \\
\mathrm{a}(\mathrm{nm}) *\end{array}$ & $\mathrm{C}_{\text {lig }}(\mathrm{mmol} / \mathrm{g})$ \\
\hline PMO-ICS-10 & 586 & 1.11 & 10.26 & - & 0.34 \\
\hline PMO-ICS-25 & 622 & 0.81 & 7.99 & 12.15 & 0.81 \\
\hline PMO-ICS-50 & 610 & 0.74 & 8.09 & 12.91 & 1.07 \\
\hline PMO-ICS-75 & 515 & 0.54 & 7.32 & 13.53 & 1.38 \\
\hline PMO-ICS-90 & 266 & 0.37 & 8.14 & 14.99 & 1.68 \\
\hline
\end{tabular}

* The unit cell values correspond to the (100) reflection for P6mm symmetry group; note that the same calculation procedure was used for the PMO-ICS-p samples with $\mathrm{p}=50$, 75 and 90 despite their worm-like structure.

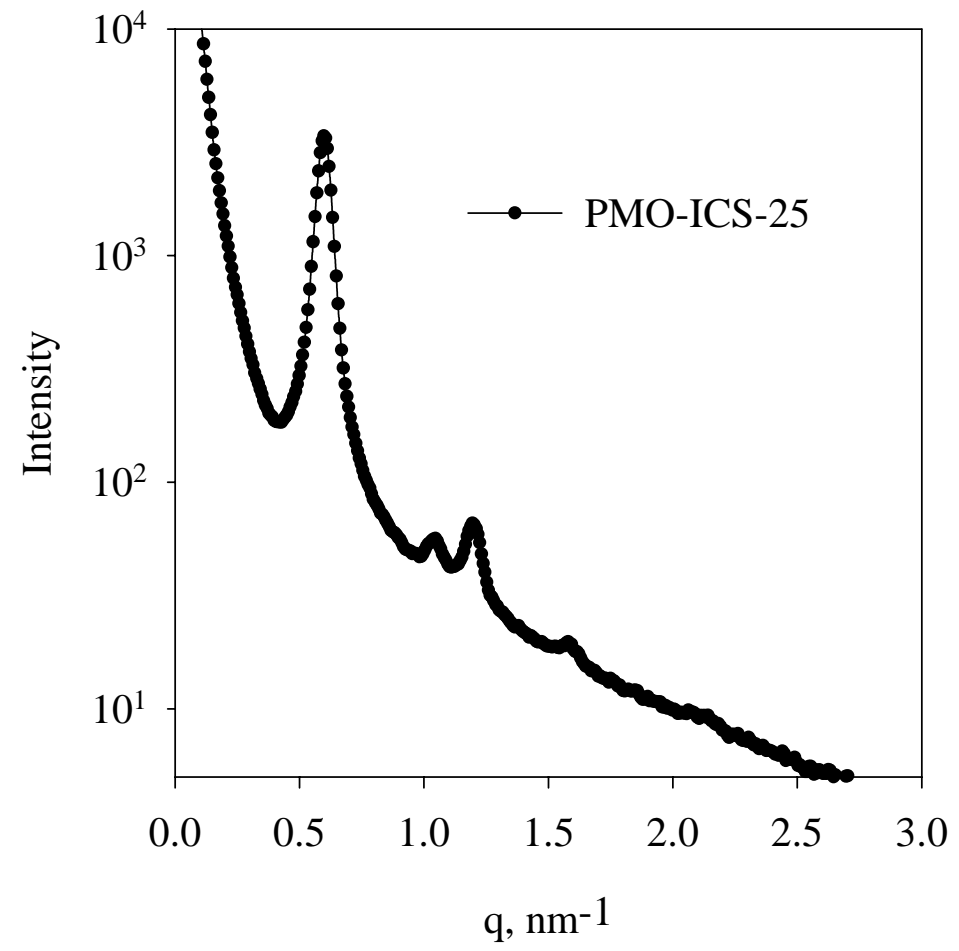

Figure 1S. Small angle X-ray scattering (SAXS) spectrum for the PMO-ICS 25 sample. The SAXS measurements were conducted using the NanoSTAR system (Bruker AXS) with pinhole collimation and a two-dimensional detector (HiSTAR), mounted on a micro focus X-ray tube with copper anode and equipped with crossed Göbel mirrors. The sample-to-detector distance was $650 \mathrm{~mm}$. The exposure time for a single frame was, $5000-10000 \mathrm{~s}$. All measurements were performed at room temperature. 
(C) American Chemical Society, J. Am. Chem. Soc., JA043941A, Supporting Info Page S3

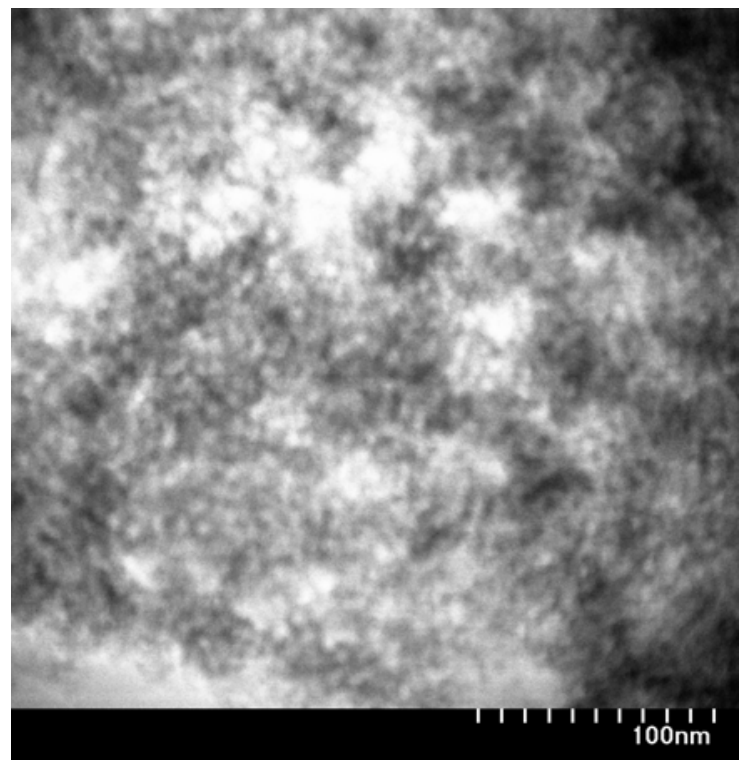

Figure 2S. Transmission electron microscopy (TEM) image for PMO-ICS-50 sample. The TEM analysis was performed on a Hitachi HD2000 STEM with a voltage of $200 \mathrm{kV}$ and a current of 30 micro-A(uA).

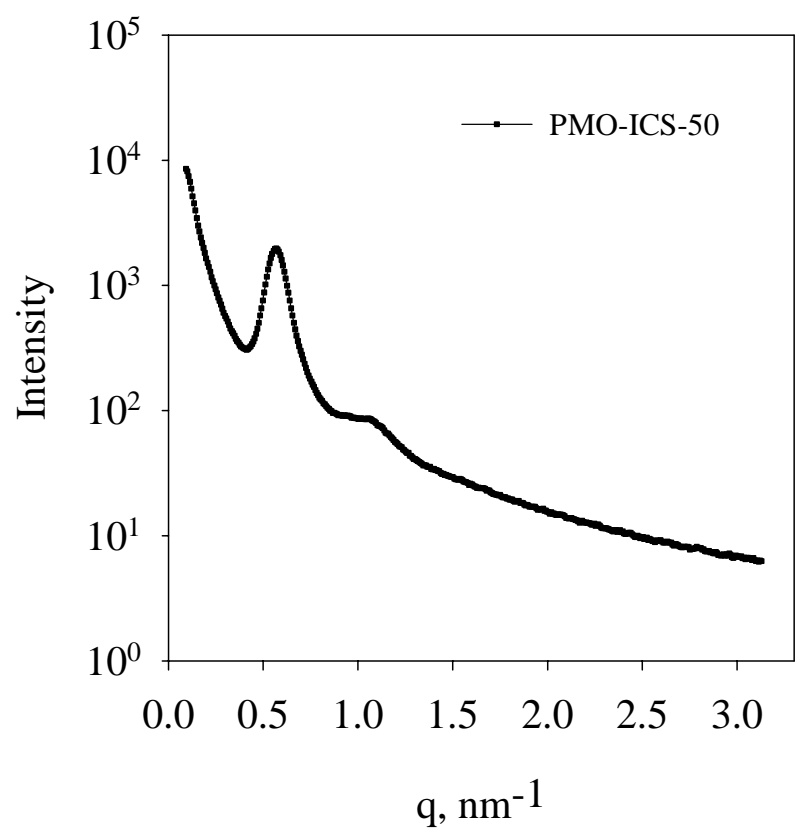

Figure3S. SAXS spectrum for the PMO-ICS 50 sample. For experimental details see caption under Figure 1S. 
(C) American Chemical Society, J. Am. Chem. Soc., JA043941A, Supporting Info Page S4

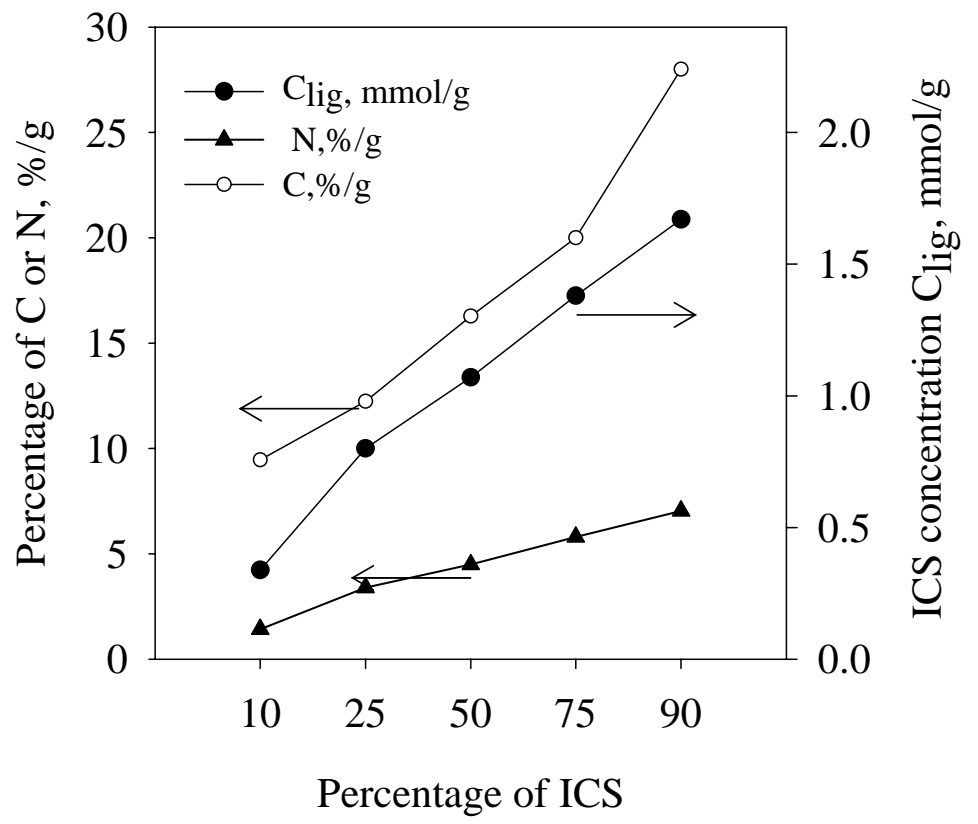

Figure 4S. Elemental analysis data (C\% and N\%) and the ICS concentration in PMOs as a function of the percentage of ICS in the synthesis gel. The C\% and N\% data were determined using a LECO Model CHNS-932 elemental analyzer (St. Joseph, MI).

Table 2S. Comparison of the theoretical and experimental values of the nitrogen content and ligand concentration for periodic mesoporous organosilicas (PMO) with bridging tris[3(trimethoxysilyl)propyl]isocyanurate (ISC) groups.*

\begin{tabular}{|c|c|c|c|c|c|c|}
\hline Sample & \multicolumn{2}{|c|}{$\begin{array}{c}\text { N\% and Clig predicted on the basis of } \\
\text { the gel composition used in the } \\
\text { synthesis }\end{array}$} & \multicolumn{3}{|c|}{$\begin{array}{c}\text { The ICS/TEOS ratio and } C_{\text {lig }} \\
\text { estimated from N\% obtained by } \\
\text { elemental analysis }\end{array}$} \\
\hline & $\begin{array}{c}\text { ICS/TEOS, } \\
\mathrm{mol} / \mathrm{mol}\end{array}$ & $\begin{array}{c}\mathrm{N}, \\
\%\end{array}$ & $\begin{array}{c}\mathrm{C}_{\text {lig, }} \\
\mathrm{mmol} / \mathrm{g}\end{array}$ & $\begin{array}{c}\text { ICS/TEOS, } \\
\mathrm{mol} / \mathrm{mol}\end{array}$ & $\begin{array}{c}\mathrm{N}, \\
\%\end{array}$ & $\begin{array}{c}\mathrm{C}_{\text {lig, }} \\
\mathrm{mmol} / \mathrm{g}\end{array}$ \\
\hline PMO-ICS-10 & $0.033 / 0.967$ & 1.95 & 0.47 & $0.023 / 0.977$ & 1.4 & 0.34 \\
\hline PMO-ICS-25 & $0.083 / 0.917$ & 3.93 & 0.93 & $0.067 / 0.932$ & 3.4 & 0.81 \\
\hline PMO-ICS-50 & $0.167 / 0.833$ & 5.93 & 1.41 & $0.103 / 0.897$ & 4.5 & 1.07 \\
\hline PMO-ICS-75 & $0.25 / 0.75$ & 7.13 & 1.69 & $0.159 / 0.840$ & 5.8 & 1.38 \\
\hline PMO-ICS-90 & $0.3 / 0.7$ & 7.65 & 1.82 & $0.242 / 0.758$ & 7.0 & 1.68 \\
\hline
\end{tabular}

* The values of $\mathrm{N} \%$ and $\mathrm{C}_{\mathrm{lig}}$ were calculated by using the molecular weight (MW) of the incorporated part of ICS into the PMO structure, i.e., MW of ICS without $\mathrm{CH}_{3} \mathrm{O}_{1 / 2}$ groups. For TEOS, the molecular weight of TEOS without $\mathrm{C}_{2} \mathrm{H}_{5} \mathrm{O}_{1 / 2}$ groups was used. No correction was made to account for silanol groups. Also, it was assumed that all alkoxy groups were hydrolyzed. 
() American Chemical Society, J. Am. Chem. Soc., JA043941A, Supporting Info Page S5

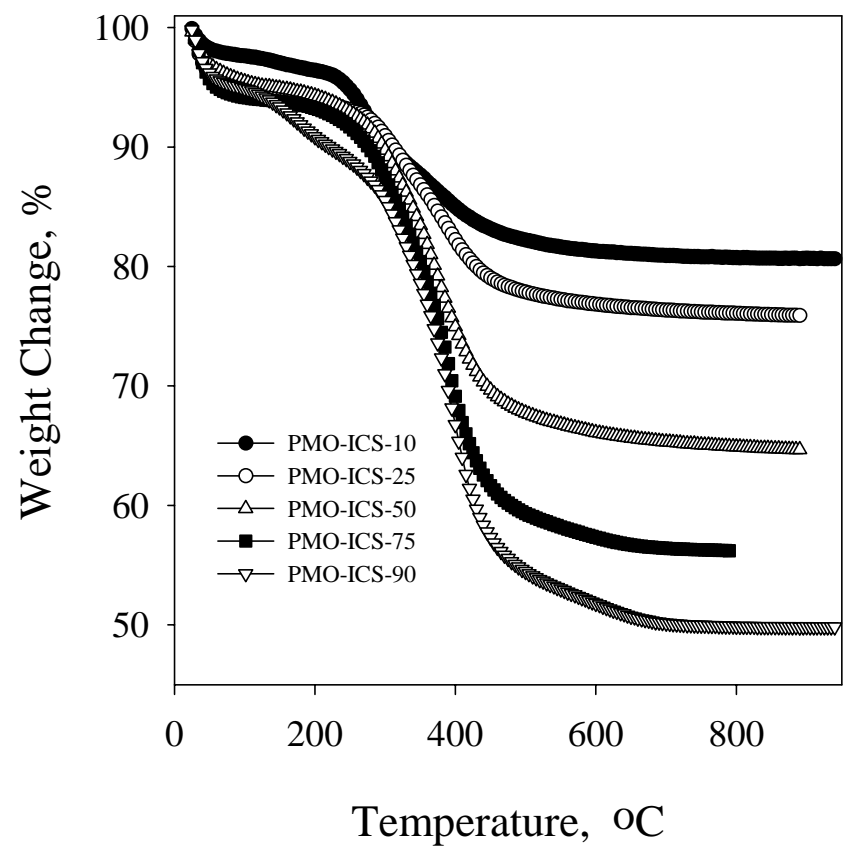

Figure 5S. The TG weight change curves for the extracted PMO-ICS samples with different percentage of ICS used in the synthesis. These curves were recorded under air on a TA Instruments TGA 2950 high-resolution thermogravimetric analyzer in a high-resolution mode with the maximum heating rate of $5 \mathrm{deg} / \mathrm{min}$.

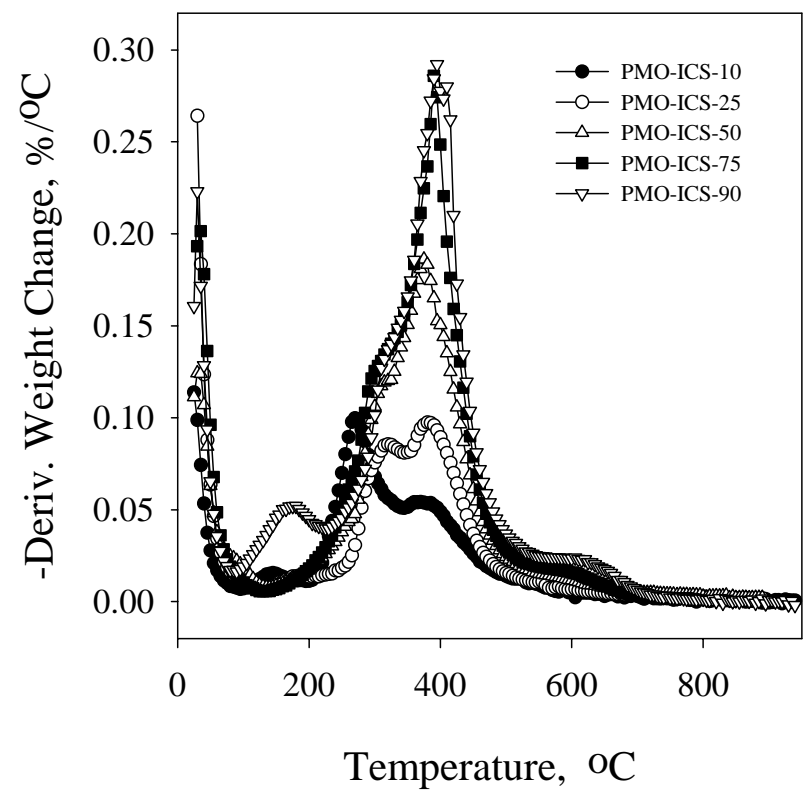

Figure 6S. The DTG curves corresponding to the TG curves shown in Figure $5 \mathrm{~S}$ for the extracted PMO-ICS samples synthesized using different percentages of ICS. 
(C) American Chemical Society, J. Am. Chem. Soc., JA043941A, Supporting Info Page S6

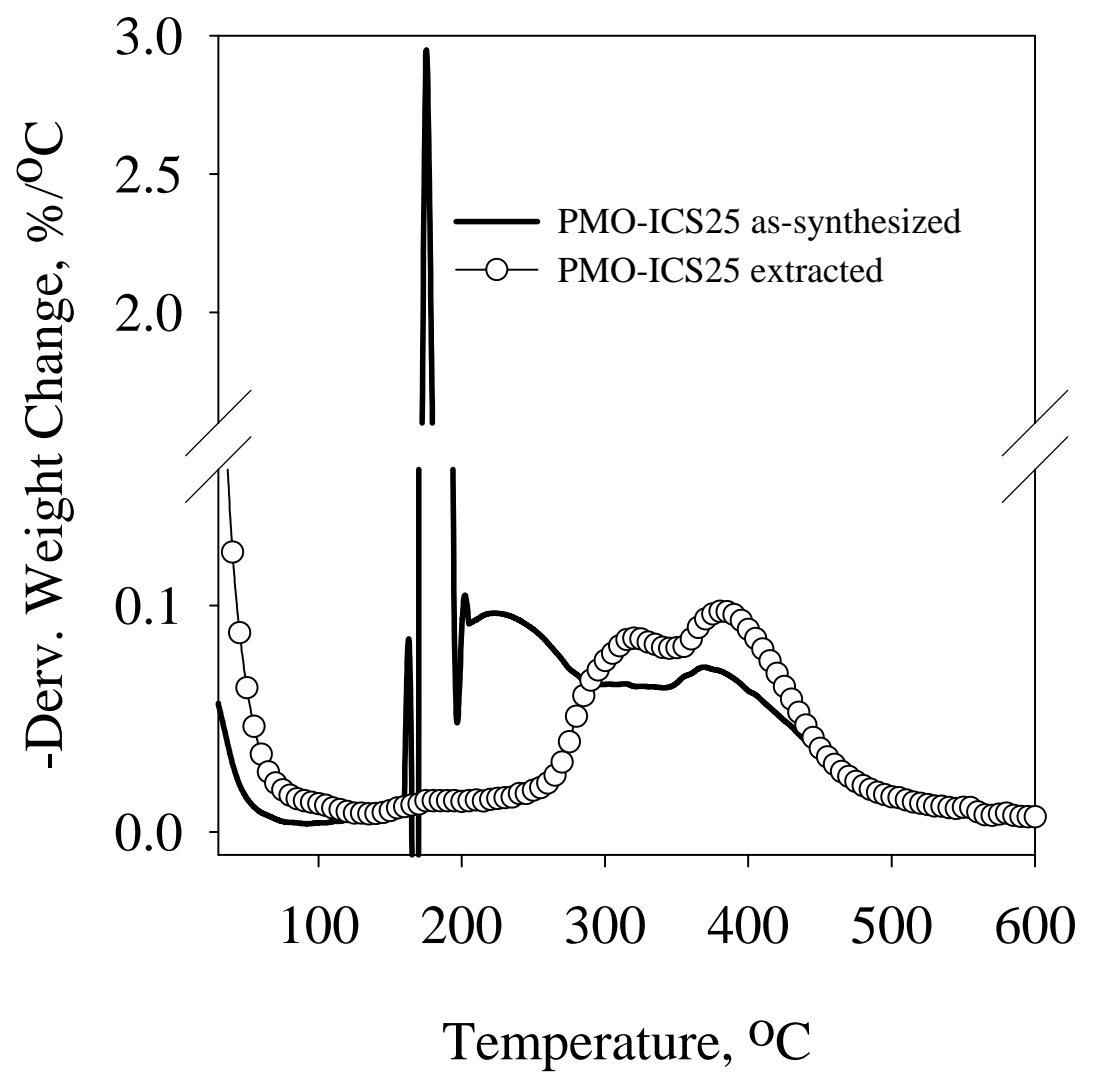

Figure 7S. Comparison of the DTG curves for the as-synthesized and extracted PMO-ICS-25 samples. The sharp peak (solid line) about $170^{\circ} \mathrm{C}$ reflects thermodesorption/decomposition of the polymeric template from the as-synthesized sample. The DTG profile above $200^{\circ} \mathrm{C}$ reflects mainly decomposition of the incorporated isocyanurate bridging groups from this sample. Since polymer template was effectively removed by extraction the aforementioned sharp peak is not present on the DTG curve for the corresponding extracted sample (solid line with open circles). 


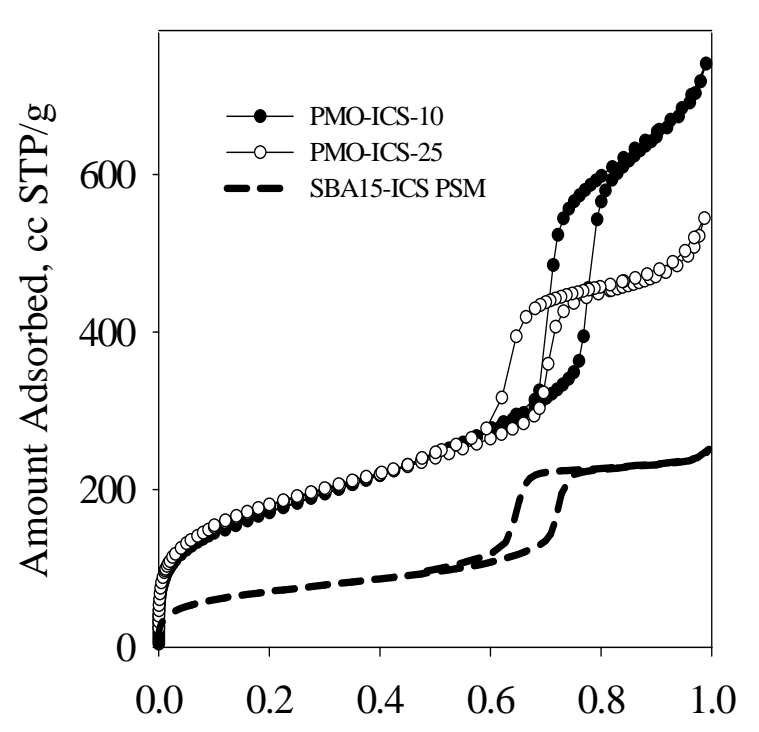

Relative Pressure

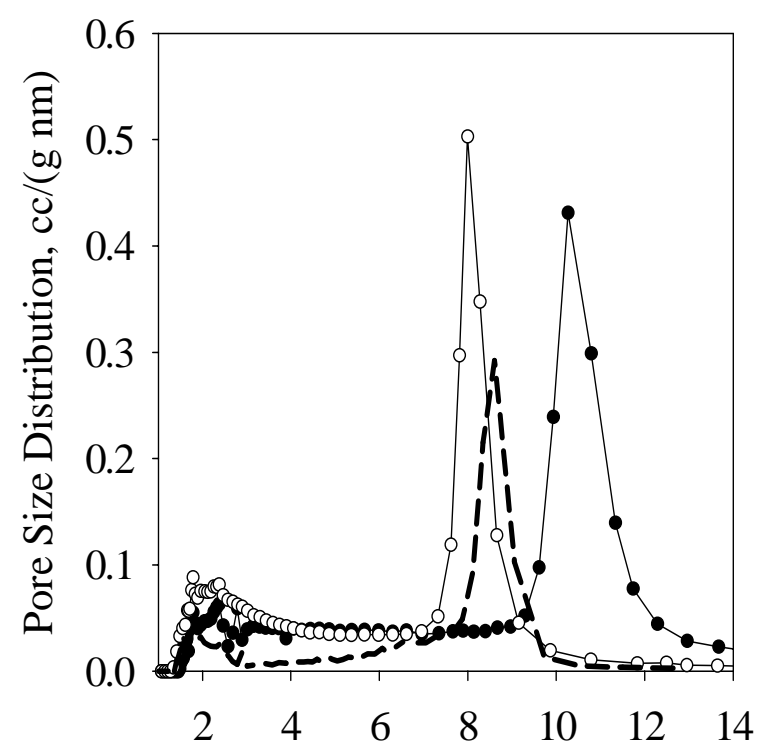

Pore Width, nm

Figure 8S. Nitrogen adsorption isotherms measured at $-196^{\circ} \mathrm{C}$ and the corresponding pore size distribution for two samples obtained by one-pot co-condensation synthesis with tris[3(trimethoxysilyl)propyl]isocyanurate (PMO-ICS-10, PMO-ICS-25) and the SBA-15 sample modified by post-synthesis grafting with tris[3-(trimethoxysilyl)propyl]isocyanurate.

Nitrogen adsorption measurements were carried out using a Micromeritics ASAP 2010 volumetric adsorption analyzer. Before adsorption measurements each sample was outgassed for at least two hours at $120^{\circ} \mathrm{C}$.

The ICS/SiO ${ }_{2}$ ratio used in the post-synthesis modification of SBA15 was equal to $0.1 / 0.9$ (which was comparable to that used in the synthesis of PMO-ICS-25). The nitrogen percentage in this synthesis mixture was about $4.1 \%$, which should give the ligand coverage of $\sim 1 \mathrm{mmol} / \mathrm{g}$ if $100 \%$ of ICS is attached to the silica surface. The nitrogen content in the SBA15-ICS PSM sample obtained by elemental analysis was equal to $2.14 \%$, which corresponds to the ligand coverage of $\sim 0.5 \mathrm{mmol} / \mathrm{g}$. These data show that only about $50 \%$ of the ICS used was attached to the silica surface during post-synthesis modification. Note that for a similar amount of the ICS used in two different syntheses, one-pot synthesis gave the sample with much larger amount of ICS incorporated into PMO than the amount attached to the SBA15 surface during post-synthesis modification. Also, the SBA15-ICS PSM sample had much smaller BET surface area $\left(245 \mathrm{~m}^{2} / \mathrm{g}\right)$ and pore volume $(0.38 \mathrm{cc} / \mathrm{g})$ than those for a PMO-ICS sample with analogous amount of incorporated ICS (see Table 1S). 